\title{
Comparison Of Three Numerical Methods For Estimating Weibull Parameters Using Weibull Distribution Model In Nigeria
}

\author{
*J. A. Oyewole, F. O. Aweda and D. Oni \\ Department of Physics and Solar Energy, Bowen University, Iwo, Osun State \\ [*Corresponding Author: Email: *joeademola@gmail.com, joshua.oyewole@bowenuniversity.edu.ng]
}

\begin{abstract}
\end{abstract}
There is a crucial need in Nigeria to enhance the development of wind technology in order to boost our energy supply. Adequate knowledge about the wind speed distribution becomes very essential in the establishment of Wind Energy Conversion Systems (WECS). Weibull Probability Density Function (PDF) with two parameters is widely accepted and is commonly used for modelling, characterizing and predicting wind resource and wind power, as well as assessing optimum performance of WECS. Therefore, it is paramount to precisely estimate the scale and shape parameters for all regions or sites of interest. Here, wind data from year 2000 to 2010 for four different locations (Port Harcourt, Ikeja, Kano and Jos) were analysed and the Weibull parameters was determined. The three methods employed are Mean Standard Deviation Method (MSDM), Energy Pattern Factor Method (EPFM) and Method of Moments (MOM) for estimating Weibull parameters. The method that gave the most accurate estimation of the wind speed was MSDM method, while Energy Pattern Factor Method (EPFM) is the most reliable and consistent method for estimating probability density function of wind.

Keywords: Weibull Distribution, Method of Moment, Mean Standard Deviation Method, Energy Pattern Method

\section{INTRODUCTION}

In the last few decades, wind energy is fast gaining acceptability as an economical energy source around the world and with great investors showing interest in the technology involved. A reasonable percentage of the world population today do not have access to grid electricity (International energy agency, 2012), but wind energy can be used in rural and remote regions. The challenge of fast growing population in Nigeria and the high drive for industrialization has resulted to a growing demand for power. Wind energy as one of the sources for electricity production is being vigorously pursued in many countries (Dhunny et al., 2014). The distribution of wind speed is important for power generators. Weibull distribution among other types has been shown to fit the wind probability distribution (Pishgar-Komleh et al., 2015). The Weibull distribution is one of the widely used distributions in technical practice. It is often used in weather forecasting. This distribution was first introduced by the Swedish scientist Walodi Weibull (1887-1979), who used it in the theory of reliability (Ivana and Zuzana, 2014). Weibull distribution is found useful to model wind speed distribution at any site of interest and hence can be used to address the wind resource assessment of a site. If the shape and scale parameters of Weibull distribution function are determined, the average velocity can be predicted by Weibull and Rayleigh distribution (Ahmed, 2013) and this is the key to construction of Wind turbine and wind farm energy calculations.

Several methods have been proposed to estimate wind energy potential (Asiegbu and Iwuoha, 2007; Munteanu et al., 2008; Olayinka and Olaolu, 2012) including the use of statistical analysis to describe wind profile based on Weibull function (Justus et al., 1978; Martin et al., 1999; Chang, 2011a; Chang, 2011b; Waewsak et al., 2011; Dieudonn et al., 2014; Mert and Karakus, 2014). However, the import of this work is to rank the three common methods: Mean Standard Deviation Method (MSDM), Method of Moment (MOM) and Energy Pattern Factor Method (EPFM) to estimate the wind energy potential in the order of their effectiveness. 


\section{MATERIALS AND METHODS \\ Study Area}

Two locations were selected from the coastal and inland areas of Nigeria i.e. Port Harcourt (Longitude $7.05 \mathrm{E}$ and Latitude $4.81 \mathrm{~N}$ ) in Rivers State and Ikeja (longitude $3.35 \mathrm{E}$ and latitude $6.60 \mathrm{~N}$ ) in Lagos State, both bathed by the Atlantic ocean to the south have tropical wet climate and the vegetation is rain forest. The other two locations in the inland areas are Jos, Plateau State and Kano in Kano State. Jos (longitude $8.53 \mathrm{E}$ and latitude9.56 N) in the north central part of Nigeria with an altitude of $1217 \mathrm{~m}$ (3999ft) above sea level; lies guinea savannah belt and has a more temperate climate than the remaining parts of Nigeria. Kano (longitude $8.59 \mathrm{E}$ and latitude12.00 N) is in the north western part of Nigeria. It is in the Sahelian geographic region, south of Sahara. It is the third largest city in Nigeria. .

\section{Data collection and Analyses}

The data for this study was obtained from archives of Nigeria Meteorological Agency (NIMET) at Oshodi, Lagos which covers 11 year period $(2000-2010)$ of daily wind speed measured at 10 meters height from the surface in the area under study. Data was analysed using three methods: Mean Standard Deviation Method (MSDM), Method of Moment (MOM) and Energy Pattern Factor Method (EPFM). Parameters are here presented below.

\section{Weibull Distribution Parameters}

The Weibull distribution is characterized by two parameters, one is the scale parameter, $c$ $(\mathrm{m} / \mathrm{s})$ and the other is the shape parameter, $k$ (dimensionless). In Weibull distribution, the variations in wind speed are characterized by two functions which are the probability density function (PDF) and the cumulative distribution function (CDF). PDF indicates the fraction of time (or probability) for which the wind is at a given speed $V$. It is given by equation 1 .

$f_{(v, k, c)}=\frac{K}{C}\left[\frac{V}{C}\right]^{K-1} e^{-\left(\frac{V}{C}\right)^{K}}$
Where $\mathrm{v}>0$, and $\mathrm{k}, \mathrm{c}>0 . K$ is the weibull shape parameters which is dimensionless, $C$ is the scale parameter measured in $\mathrm{m} / \mathrm{s}$, $f_{(v, k, c)}$ is the probability of observing wind speed $v(\mathrm{~m} / \mathrm{s})$. The CDF of the speed $V$ gives the fraction of the time (or probability) that the wind speed is equal or lower than $\mathrm{V}$, thus, the cumulative distribution is the integral of the PDF, given by:

$f_{(v, k, c)}=\int_{0}^{\infty} f(V) d v=1-e^{-\left(\frac{V}{c}\right)^{K}}$

The average wind speed can be expressed as:

$$
\begin{aligned}
& \bar{V}=\int_{0}^{\infty} f(V) d v \\
& \bar{V}=\int_{0}^{\infty} V \frac{K}{C}\left(\frac{V}{C}\right)^{K-1} e^{-\left(\frac{V}{C}\right)^{K} d v}
\end{aligned}
$$

This can be rearranged as: $\bar{v}=$ $\int_{0}^{\infty}\left(\frac{V}{C}\right)^{K} e^{-\left(\frac{V}{C}\right)^{K} d V}$

Taken $x=\left(\frac{v}{c}\right)^{k}, d V=\frac{c}{k} x^{\left[\frac{1}{k}-1\right]}$

Equation 5 can be simplified as:

$\bar{V}=c \int_{0}^{\infty} e^{-x} x^{1 / k} d x$

This is the form of the standard gamma function, which is given by:

$\Gamma n=\int_{0}^{\infty} e^{-x} x^{n-1} d x$

From Equations 7 and 8 , let $n=1+1 / k$ the average speed can be expressed as:

$\bar{V}=c \Gamma\left(1+\frac{1}{k}\right)$

Where $f(V)$ is Weibull cumulative distribution function, $\bar{V}$ is the average wind speed Various methods for Estimating Weibull Parameters used in this study are as discussed below:

\section{Mean Standard Deviation Method (MSDM)} MSDM need at least two parameters and these are mean wind speed and standard deviations. It is well known empirical method and could be considered as a unique case of MOM, Weibull shape and scale parameters are estimated by: 


$$
\begin{aligned}
& K=\left(\frac{\sigma}{\bar{V}}\right)^{-1.086} \\
& C=\frac{\bar{V}}{\Gamma\left(1+\frac{1}{k}\right)}
\end{aligned}
$$

Where $\sigma$ the standard deviation and $\bar{v}$ is the mean wind speed (in metre per second). Alternatively, Weibull scale parameter, $\mathrm{C}$ can be projected from the following expression given by:

$$
C=\frac{\bar{V} K^{2.6674}}{0.184+0.816 K^{2.73855}}
$$

(Shiva and Satyanarayana, 2015)

\section{Method of Moments (MOM)}

MOM is one of the imperative techniques universally used in the field for evaluating Weibull parameters. It is based on the numerical iteration of mean wind speed and standard deviations of wind speed (Shiva et al., 2015).

Mean wind speed, $\bar{v}$ and variance of data shall be calculated beforehand then value of $K$ and $C$ can be

Obtained from:

$$
\begin{aligned}
& K=\left[\frac{0.9874}{\sigma / \bar{V}}\right]^{1.0983} \\
& C=\frac{\bar{V}}{\Gamma\left(1+\frac{1}{K}\right)}
\end{aligned}
$$

Where $\Gamma$ is the gamma function

$$
\begin{aligned}
& \Gamma n=\int_{0}^{\infty} e^{-x} x^{n-1} d x \quad \text { (16) (Ayush, } \\
& \text { 2016) }
\end{aligned}
$$

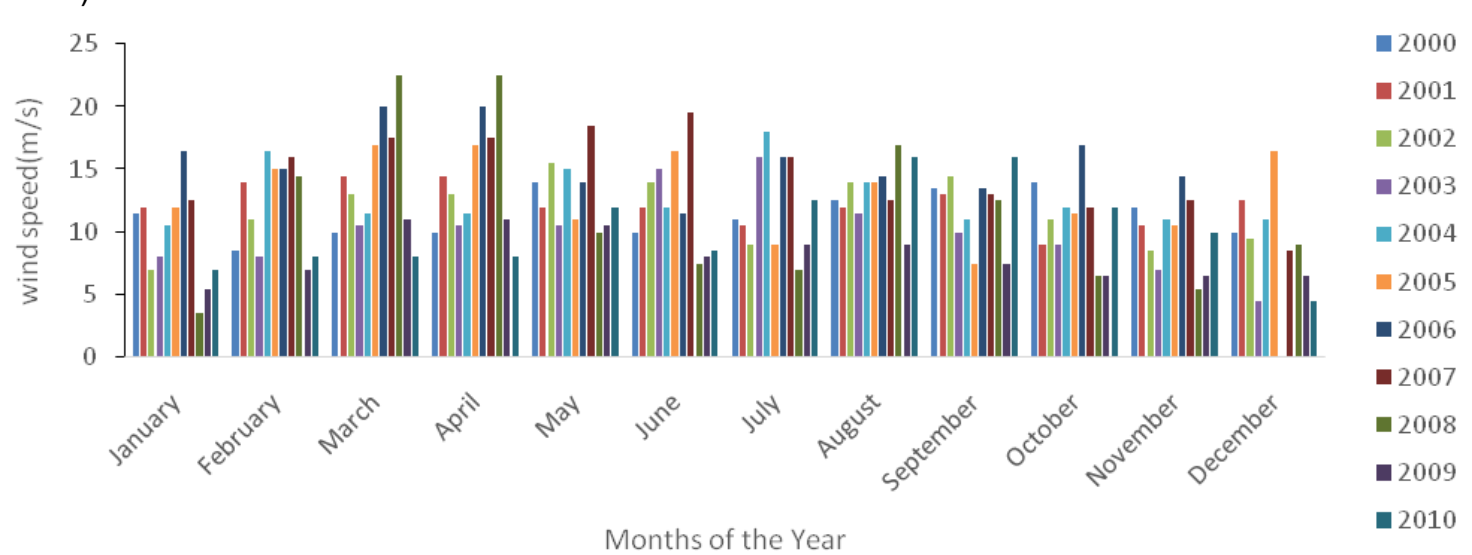

Figure 1a: Wind speed variation recordedfor Ikeja from 2000 - 2010

\section{Energy Pattern Factor Method (EPFM)}

The Energy pattern factor is connected to the average data of wind speed and can be defined by the equation 17 .

$E P F=\frac{1}{\bar{V}^{3}}\left(\frac{\sum_{i=1}^{n} V^{3} i}{n}\right)$

Where $v_{i}$ is the wind speed in meter per second for ith observation, $\mathrm{n}$ is the total number of wind speed observations, and $\bar{v}$ is the mean wind speed. Parameters $\mathrm{k}$ and $\mathrm{c}$ is calculated from the following formulas:

$$
\begin{aligned}
& K=1+\frac{3.69}{(E P F)^{2}} \\
& C=\frac{V}{\Gamma\left(1 \div \frac{1}{K}\right)}
\end{aligned}
$$

\section{RESULTS}

The mean wind speeds, PDF, calculated shape factor and scale parameter determined from equations 11-19 for each of the three numerical methods considered in the analysis are presented in Figures 1, 2 and 3.

Figure 1 shows the representation of mean wind speed variations in the four different locations for January to December (2000 2010). 


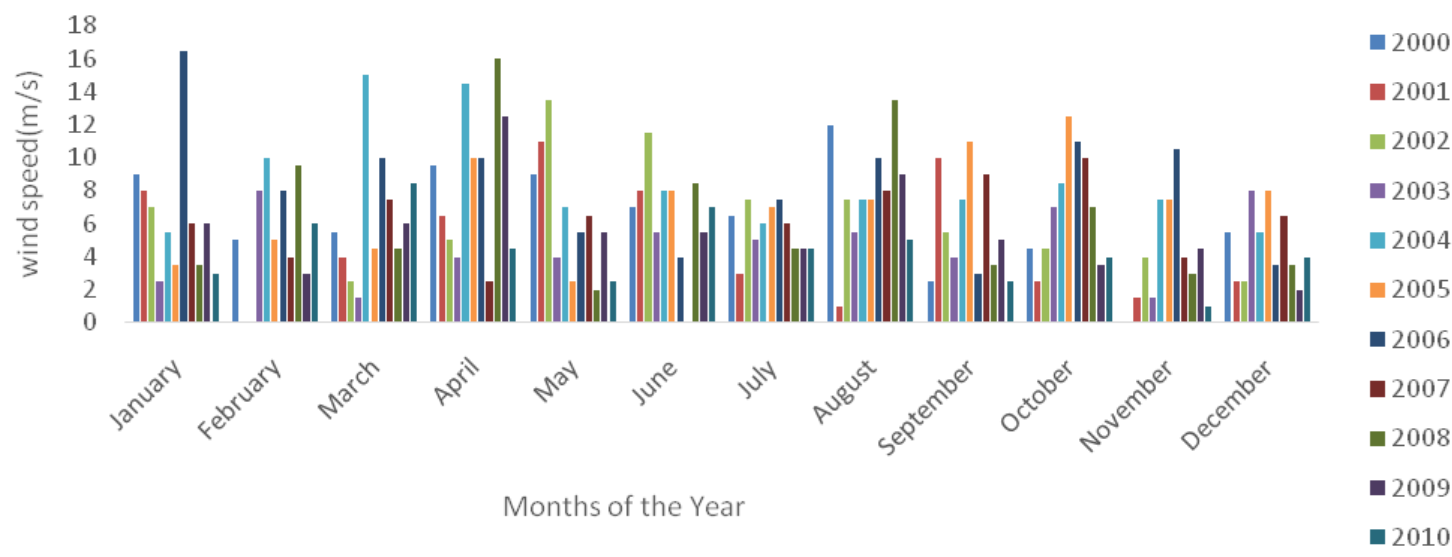

Figure 1b: Wind speed variation recorded for Port Harcourt from 2000 - 2010

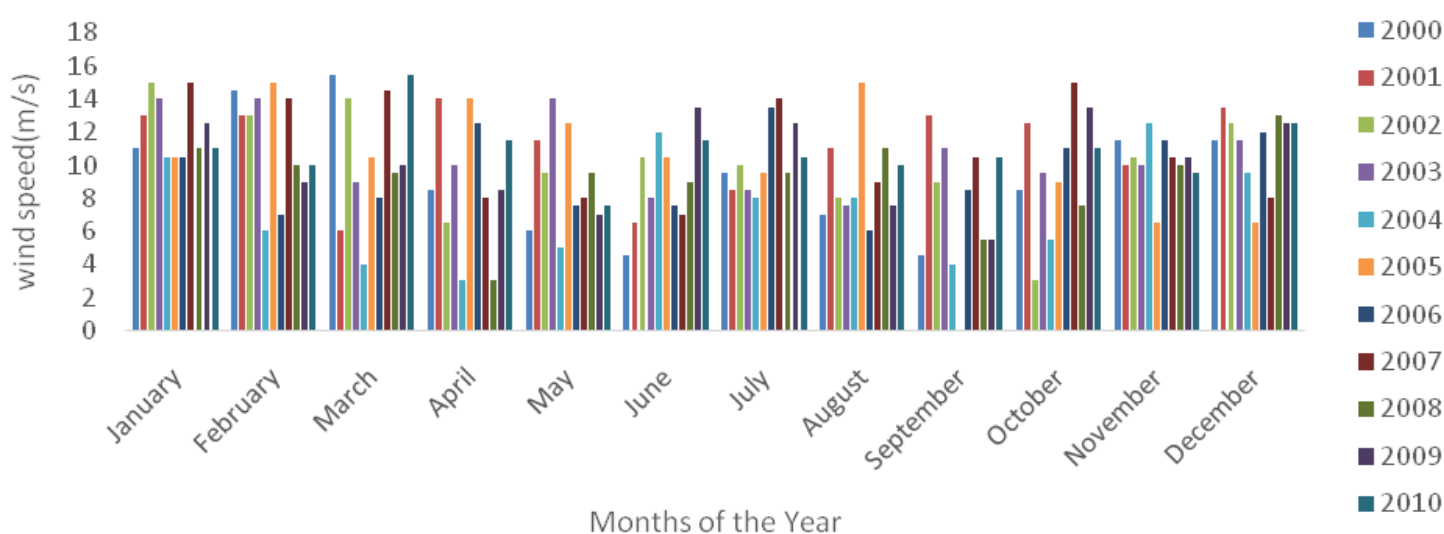

Figure 1c: Wind speed variation recorded for Kano from 2000 - 2010

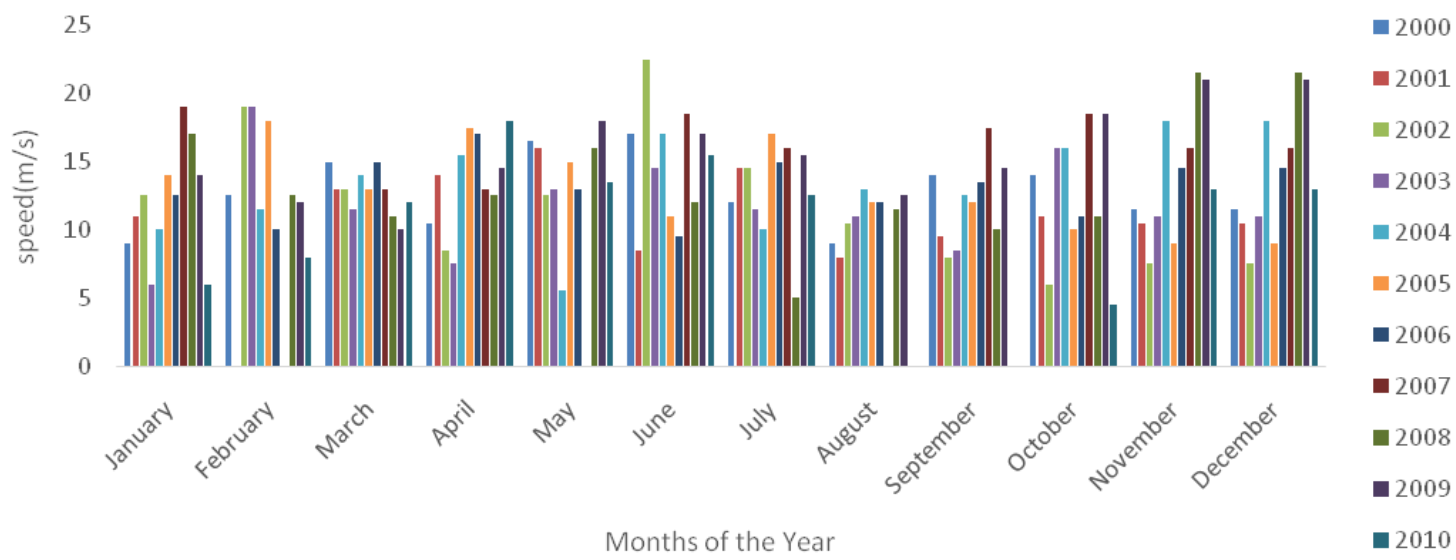

Figure 1d: Wind speed variation recorded for Jos from 2000 - 2010

The comparison of the three methods presented in Figure $2(a-h)$ showing the probability distribution Function (PDF) of a sample of two months (January and February) from the four locations. 
Oyewole et al: Comparison Of Three Numerical Methods For Estimating Weibull.........

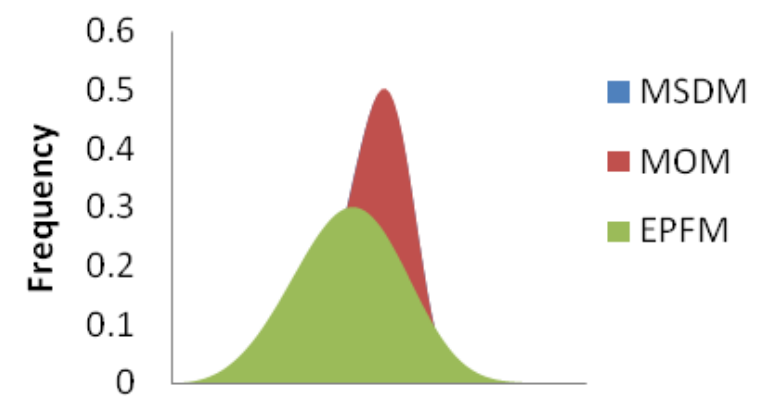

0.11 .42 .745 .36 .67 .99 .2

Wind Speed $(\mathrm{m} / \mathrm{s})$

Figure 2a: Probability Distribution Function for Jan. Port Harcourt

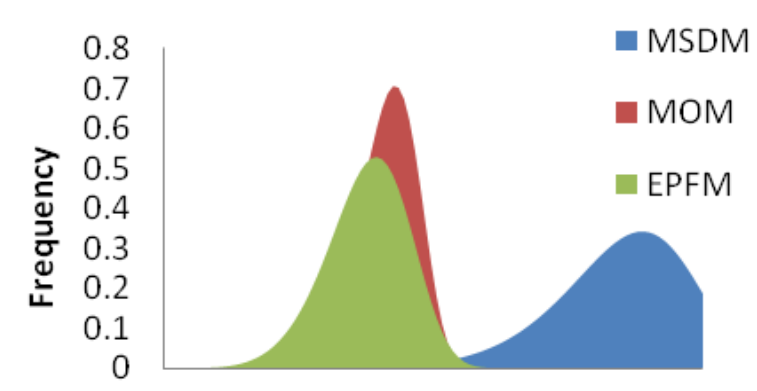

0.11 .12 .13 .14 .15 .16 .17 .18 .19 .1

Wind Speed $(\mathrm{m} / \mathrm{s})$

Figure 2b: Probability Distribution Function for Feb. in Port Harcourt

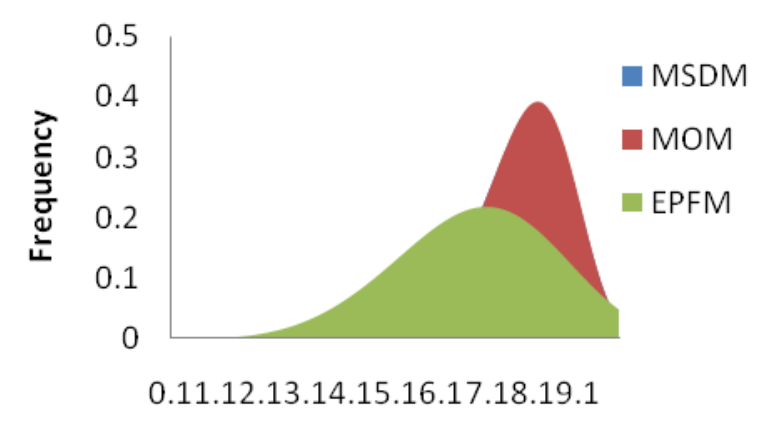

Wind Speed $(\mathrm{m} / \mathrm{s})$

Figure 2c: Probability Distribution Function for Jan. in lkeja

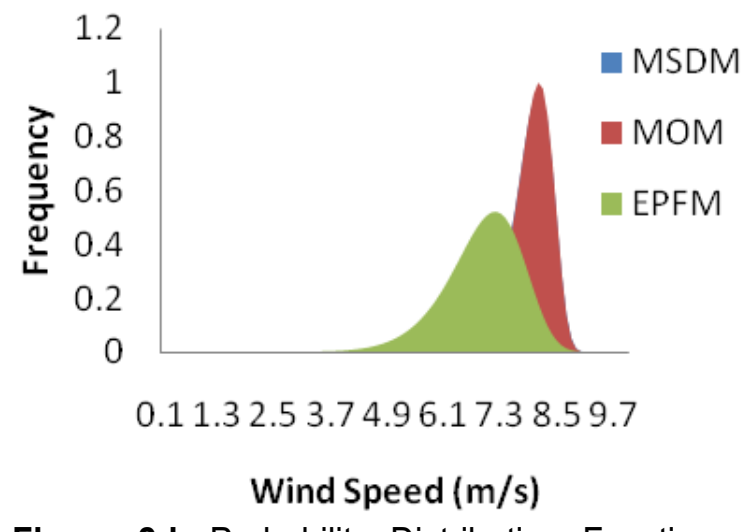

Figure 2d: Probability Distribution Function for Feb. in Ikeja

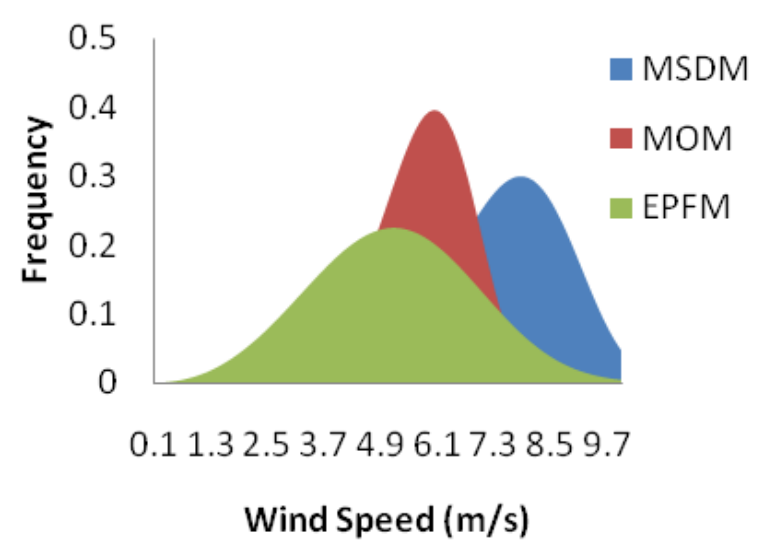

Figure 2e: Probability Distribution Function for Jan. in Jos.

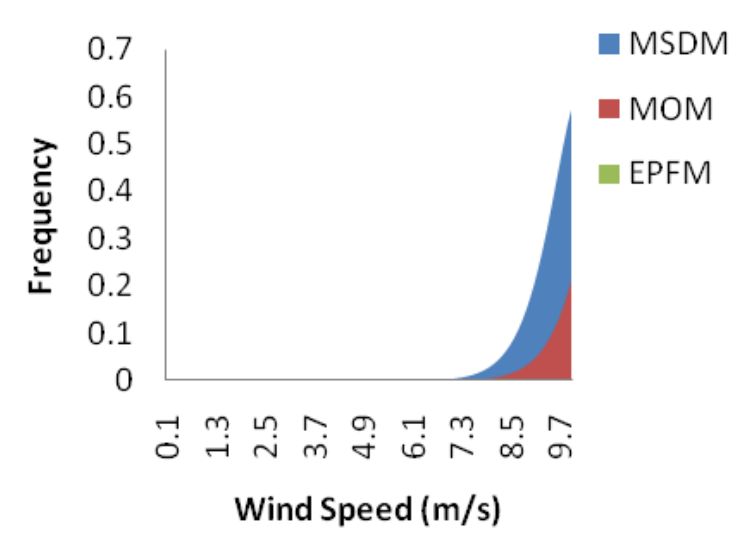

Figure 2f: Probability Distribution Function for Feb. in Jos. 


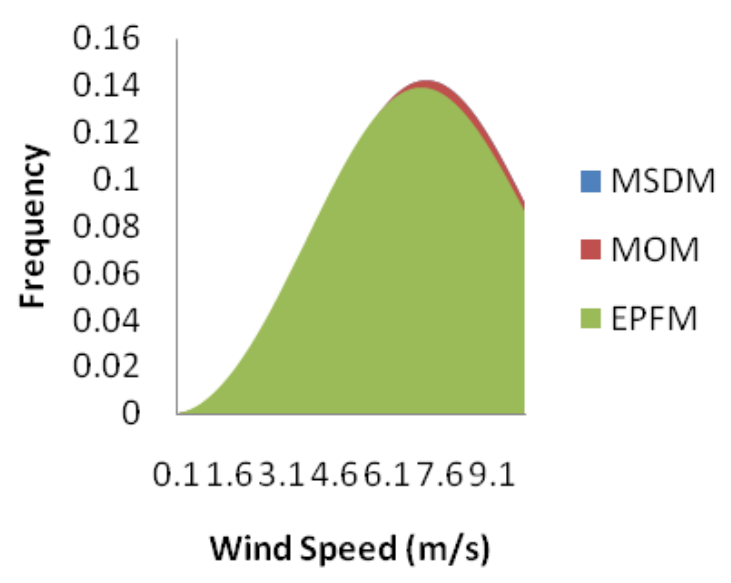

Figure 2g: Probability Distribution Function For Jan. in Kano

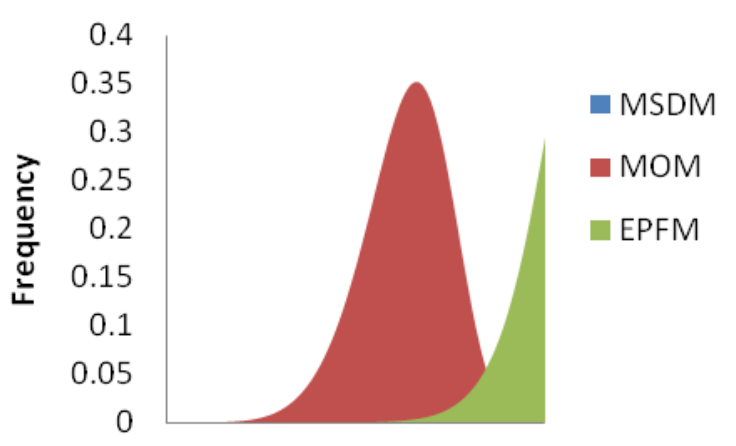

0.11 .42 .745 .36 .67 .99 .2

Wind Speed $(\mathrm{m} / \mathrm{s})$

Figure 2h: Probability Distribution function for Feb.in Kano

Mean wind speed obtained from the scale parameters computed from the Mean Standard Deviation Method (MSDM), Method of Moments (MOM), and Energy Pattern Factor Method (EPFM), i.e. using equations 12, 15 and 19 for each station were compared. The month of January was chosen as sample for each location as presented in Figures $3(a-d)$.

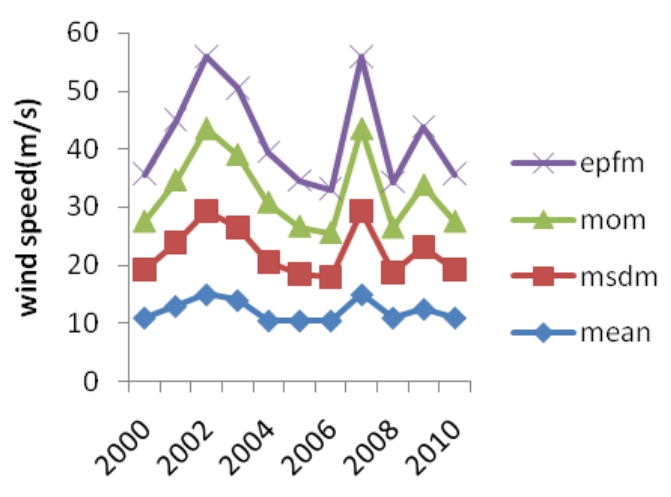

Figure 3a: Comparison of mean wind speeds obtained from the three methods and the mean speeds from the Weibull for Jan. (20002010) for Kano

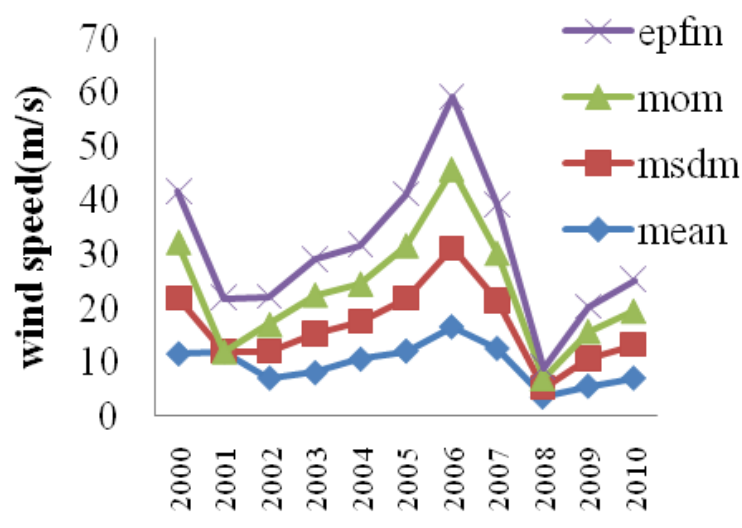

Figure 3b: Comparison of mean wind speeds obtained from the three methods and the mean speeds from the Weibull for Jan. (20002010) for lkeja.

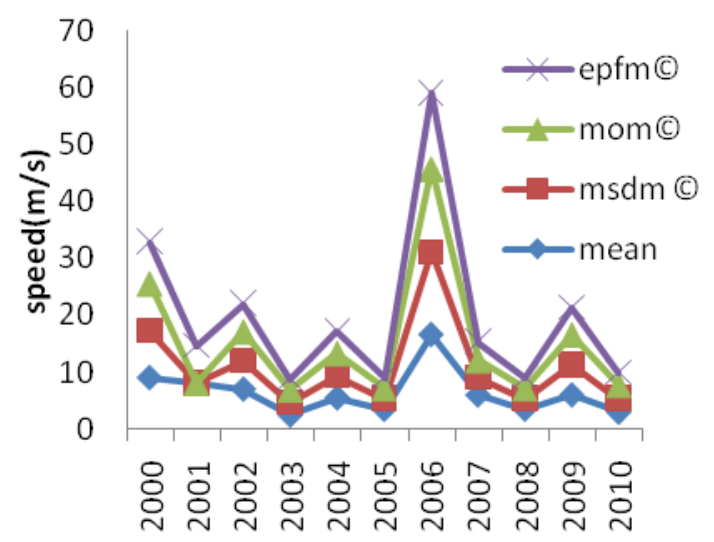

Figure 3c: Comparison of mean wind speeds obtained from the three methods and the mean speeds from the Weibull for Jan. (20002010) Port Harcourt 


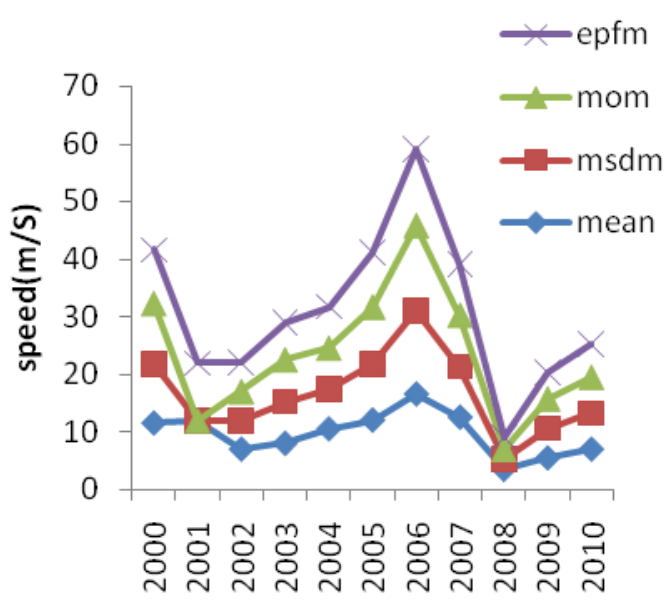

Figure 3d: Comparison of mean wind speeds obtained from the three methods and the mean speeds from the Weibull for Jan. (20002010) for Jos

\section{DISCUSSION}

In the case of Weibull distribution, no method provides an explicit solution for the estimates of the parameters using their various relations, but according to Pishgar-Komleh et al, (2015) Weibull still remain the best distribution that fit the wind probability distribution more exactly. However, the performance of these methods is compared based on how closely they imitate the shape of normal distribution.

The Performance of the three methods were tested using the relevant equations (Shiva and Satyanarayana, 2015) and data for the four stations. Figures $1(a-d)$ gives us an overview of temporal variation of wind speed across the period of 11 years for each station. In Port Harcourt, the highest wind speed was in January 2007 but the month that had highest wind average for all the years is April. In Ikeja, two months (March and April) had the highest wind speed values in the period of study which occurred in the year 2008. In Jos, wind speed was at its peak in June 2002 while in Kano it was highest in March in the year 2000.

The results shown in Figures 2 (a-f) established that distribution shape obtained from EPFM imitates better the shape of normal distribution than MOM and MSDM. In the comparism of mean wind speeds obtained from the three methods and the mean speed from the Weibull, the results suggests that the Mean Standard Deviation Method (MSDM) is the best of the three as it resemble the shape of the mean speed best followed by Method of Moment (MOM) and then Energy Pattern Factor Method (EPFM)in that order(figures 3a-d), which confirmed the submissions of Ahmed (2013), Asiegbu and Iwuoha (2007) and Olayinka and Olaolu (2012).

\section{CONCLUSION}

In conclusion, the proposed three methods are effective in evaluating the parameters of the Weibull distribution. However, EPFM gives a more descriptive and clear picture of the data and the behaviour of wind speed distribution in the different stations for the period under study. However, MSDM predicts the mean wind speed more accurately than the other two methods.

\section{REFERENCES}

Ahamed, S. A. (2013). Comparative study of four methods for estimating Weibull parameters for Halabja, Iraq. International Journal of Physical of Physical Sciences, 8:186-192.

Asiegbu, A. D. and Iwuoha, G. S. (2007). Studies of wind resources in Umudike, South East Nigeria-an assessment of economic viability. Journal of Engineering and Applied Sciences, 2(10): 1539-1541.

Ayush, P. (2016). A Statistical Analysis of Wind Speed and Power Density Based on Weibull and Rayleigh Models of Jumla, Nepal. Energy and Power Engineering Journal, 8(7):271282.

Chang, T. P. (2011a). Estimation of wind energy Potential using different probability density functions, Applied Energy, 88(5):1848-1856.

Chang, T. P. (2011b). Performance comparism of six numerical methods in estimating Weibull parameters for wind energy application, Applied Energy, 88(1): 272-282. 
Dhunny, A. Z., Lollehund, M. R, Boojhowon, R. and Rughooputh, S D.V. (2014). Statistical modelling of Wind Speed Data for Mauritius. International Journal of Renewable Energy Research, 4: 1056-1064.

Dieudonn, K., Danwe R., Nosi, D. and Serge, Y. (2014). Comparison of Five Methods for Estimating Weibull Parameters for Wind Energy Applications in the District of Kousseri, Cameroon. Asian Journal of Natural and Applied Sciences. 3(1): $2186-8476$.

International energy agency (2012) Annual Report. pp 1-21.

Ivana P. and Zuzana S. (2014). Comparison of Four Methods for Estimating the Weibull Distribution Parameters. Applied Mathematical Sciences. 8(83): 4137 - 4149.

Justus,C. G. Hargraves, W. R. Mikhail, A. and Graber, D.(1978). Methods for Estimating Wind Speed Frequency Distributions. Journal of Applied Meteorology (1962-1982).17(3): 350353.

Kamran A., Alamgir, Sajjad, Amjad A., Dost M. and Umar (2012). Statistical Analysis of Wind Speed Data in Pakistan. World Applied Sciences Journal, 18 (11): 1533-1539.

Martin, M., Cremades, I. V. and Santabarbara, J. M. (1999). Analysis and Modelling of time series of surface wind speed and direction. International Journal of Climatology, 19(2): 197-209.

Mert I. and Karakus C. (2014). A Statistical Analysis of wind speed data using burr, generalized gamma, and Weibull distributions in Antakya, Turkey. Turkish Journal of Electrical Engineering and Computer Sciences, 23:1571-156.

Munteanu, I., Bratcu, A. I., Cutululis, N. A., Ceanga, E. (2008). Optimal Control of Wind Energy Systems towards a Global Approach. Springer-Verlag,
University of Michigan Library, pp. 283.

Olayinka, S. O. and Olaolu, O. A. (2012). Assessment of Wind Energy potential and the economics of Wind power generation in Jos, Plateau State, Nigeria. Energy for sustainable Development 16: 78-83.

Pishgar-Komleh, S. H., Keyhani, A. and Sefeedpari, P. (2015). Wind Speed Power Density Analysis Based on Weibull and Rayleigh Distributions (A case study: Firouzkooh country of Iran). Renewable and Sustainable Energy Reviews, 42: 313-322.

Salahaddin, A. A. (2013). Comparative Study of Four Methods for Estimating Weibull Parameters for Halabja, Iraq. International Journal of Physical Sciences 8(5): 186 - 192.

Shiva, K. Prashanth K. and Satyanarayana G. (2015). Statistical Scrutiny of Weibull Parameters for Wind Energy Potential Appraisal in the Area of Northern Ethiopia. Journal of Institute of Mathematical Statistics. 39(6): 28202851

Waewsak, J. Chancham,C. Landry, M. and Gagnon, Y. (2011). An Analysis of Wind Speed Distribution at Thasala, Nakhon Si Thammarat, Thailand. Journal of Sustainable Energy \& Environment, 2:51-55. 